\title{
Rancang Bangun Sistem Monitoring Kelembaban Tanah dan Suhu Udara Berbasis GSM SIM900A DAN ARDUINO UNO
}

\author{
Wulantika Sintia, Dedy Hamdani, dan Eko Risdianto \\ Program Studi S1 Pendidikan Fisika, JPMIPA FKIP, Universitas Bengkulu \\ Jalan W.R. Supratman, KandangLimun, Bengkulu 38123 \\ Email: wulantikasintia05@gmail.com
}

\begin{abstract}
ABSTRAK
Penelitian ini bertujuan untuk merancang dan membuat alat monitoring kelembaban tanah dan suhu udara pada tanaman berbasis GSM SIM900A dan Arduino Uno, serta mengukur kelembaban tanah dan suhu udara pada tanaman berbasis GSM SIM900A dan Arduino Uno. Penelitian ini menggunakan metode Research and Development. Adapun tahap pengembangan dalam penelitian ini meliputi perencanaan, produksi, dan evaluasi. Sistem monitoring kelembaban tanah dan suhu udara tersusun atas komponen-komponen elektronika, yaitu Arduino Uno sebagai pengendali sistem dari semua rangkaian, sensor DHT11 untuk mengukur suhu udara, GSM SIM900A untuk mengirimkan SMS kepada pemilik tanaman, dan soil moisture sensor untuk mengukur kelembaban tanah, dengan cara manancapkan probe pada tanah. Jika nilai yang dihasilkan sensor kecil berarti tanah dalam keadaan lembab, dan sebaliknya. Selanjutnya, dilakukan pengujian alat secara keseluruhan untuk mengetahui apakah alat berjalan sesuai dengan tujuan. Dari hasil pengujian telah terukur bahwa sistem monitoring kelembaban tanah dan suhu udara berbasis GSM SIM900A dan Arduino Uno dapat mendeteksi kelembaban tanah dan suhu udara kemudian sms gateway bekerja secara otomatis untuk mengirimkan SMS kepada pemilik tanaman.
\end{abstract}

Kata kunci: Sensor DHT11, Soil Moisture sensor, Arduino Uno, dan GSM SIM900A

\section{ABSTRACT}

This research aims to design and make tool monitoring soil moisture and temperature on plants based GSM SIM900A and Arduino Uno, as well as to measure soil moisture and temperature on plant-based GSM SIM900A and Arduino Uno. This study uses the Research and Development. The stage of development in this research include planning, production, and evaluation. System monitoring soil moisture and air temperature are composed of electronic components, namely Arduino Uno as a control system of all circuits, sensors DHT11 to measure air temperature, GSM SIM900A to send an SMS to the owner of the plant, and soil moisture sensors to measure soil moisture, with plug in way the probe on the ground. If the value of the resulting small sensor means when moist soil, and vice versa. Furthermore, the overall testing tools to determine whether the tool run in accordance with the purpose. From the test results have been measured that soil moisture monitoring system and a GSM based air temperature SIM900A and Arduino Uno can detect soil moisture and air temperature then sms gateway works automatically to send an SMS to the owner of the plant.

Keywords: Sensor DHT11, Soil Moisture sensors, Arduino Uno, and GSM SIM900A

\section{PENDAHULUAN}

Perkembangan Ilmu Pengetahuan dan Teknologi (IPTEK) dewasa ini telah memberikan dampak dalam semua bidang kehidupan manusia, tidak terkecuali pada bidang pertanian. Zaman sekarang sudah banyak sekali teknologi canggih yang diciptakan salahsatunya teknologi dalam bidang pertanian yang dapat membantu meringankan pekerjaan petani. Indonesia yang memiliki dua musim dan sebagian besar masyarakat sebagai petani sangat mendukung pengembangan teknologi di bidang pertanian.

Salah satu komoditas yang banyak dicari dan dikonsumsi oleh masyarakat saat ini adalah sayuran. Kesadaran masyarakat tentang pentingnya hidup sehat mengakibatkan permintaan sayur meningkat. Adapun salah satu jenis sayuran yang banyak dicari dan dikonsumsi masyarakat adalah sawi, karena selain mudah diolah, sawi juga memiliki kandungan zat gizi yang dibutuhkan untuk 
tubuh. Sayuran sawi ini juga sangat baik untuk kesehatan tubuh manusia diantaranya mencegah sel kanker jahat.

Tinggal di daerah perkotaan tentunya sulit mendapatkan lahan yang luas, sehingga sebagian orang tidak dapat menyalurkan hobi berkebun. Sulitnya pemeliharaan tanaman tidak mendukung masyarakat terutama di perkotaan untuk berkebun atau bercocok tanam. Disamping dapat menyalurkan hobi berkebun dan memenuhi kebutuhan kesehatan, menanam sayuran dengan penataan yang asri juga akan menghasilkan lingkungan yang indah atau mempercantik rumah.

Penanaman sayuran memang membutuhkan perhatian khusus agar memperoleh hasil yang baik. Untuk memperoleh hasil yang baik ada beberapa faktor yang mempengaruhi yaitu kelembaban tanah dan suhu lingkungan sekitar pada tanaman, namun masyarakat saat ini selalu beranggapan bahwa menyiram tanaman setiap hari akan mendapatkan hasil yang baik pada tanaman, padahal ada berberapa komoditas sayuran yang tidak suka dengan kondisi tanah yang terlalu banyak mengandung air misalnya pada tanaman sawi, karena jika tanah pada tanaman sawi melampaui keadaan lembab yang dikehendaki dapat menyebabkan sawi tidak tumbuh dengan baik. Pada fase awal pertumbuhan sayuran sawi perlu dilakukan penyiraman secara rutin bila tanah terlihat kering, terutama pada musim kemarau. Namun pada saat musim hujan penyiraman disesuaikan dengan kondisi tanahnya. Dengan adanya penyiraman secara rutin inilah dapat menjaga kelembaban tanah [1].

Pentingnya penyiraman pada sayuran sawi, tentunya dibutuhkan perhatian khusus karena berguna untuk memantau keadaan kelembaban tanah, selain kelembaban tanah, suhu udara pada tanaman tersebut juga mempengaruhi pertumbuhan sawi. Seiring dengan aktivitas yang padat tentunya sulit memberikan perhatian khusus pada tanaman, sehingga untuk mempermudah dalam pemeliharaan tanaman khususnya pada tanaman sawi dibutuhkan suatu alat yang dapat memonitoring tanaman tersebut. Salah satu teknologi yang dapat dimanfaatkan dan mudah digunakan saat ini adalah SMS.

Ada beberapa penelitian sebelumnya yang berkaitan dengan alat monitoring kelembaban tanah dan suhu, diantaranya penelitian yang telah dilakukan oleh Prayitno, (2017) [3] tentang sistem kontrol penyiraman tanaman hidroponik dengan menggunakan blynk Arduino. Pada penelitian ini dirancang sistem yang dapat mengontrol kondisi lingkungan tanaman hidroponik dengan menggunakan ethernet shield untuk pengiriman data melalui internet, kemudian dengan aplikasi khusus android blynk penyiraman tanaman hidroponik ini dapat dipantau dan dikendalikan dari jarak jauh. Adapun pada penelitian yang akan dilakukan sistem kontrol dan pemantauannya dilakukan melalui SMS yaitu dengan menggunakan Modul GSM SIM900A, modul ini akan mengirimkan pesan tentang kondisi tanaman kepada user tanpa harus terhubung dengan internet.

Yahwe, Isnawaty, dan Aksara, (2016) [2] membahas mengenai rancang bangun prototype system untuk memonitoring kelembaban tanah dengan memanfaatkan SMS berdasarkan hasil penyiraman tanaman. Dalam penelitian ini hardware yang digunakan adalah Soil Moisture Sensor FC28 untuk mengetahui kondisi kelembaban tanah, GSM Shield ATWIN Quad-Band untuk megirimkan hasil kelembaban tanah tanaman yang diperoleh dalam bentuk SMS, dan Arduino UNO sebagai otak alat yang memproses dan mengolah data. Sedangkan pada penelitian yang akan dilakukan akan ditambahkan sensor DHT11 untuk memonitoring suhu karena selain kelembaban, faktor lainnya yang mempengaruhi pertumbuhan tanaman adalah suhu udara, sehingga dengan demikian tanaman memiliki suhu yang konstan sesuai dengan keinginan.

Berdasarkan pemikiran diatas, maka diangkatlah pemikiran tersebut dalam penelitian yang berjudul: "Rancang Bangun Sistem Monitoring Kelembaban Tanah dan Suhu Udara Berbasis GSM SIM900A dan Arduino Uno". Adapun permasalahan yang akan dibahas dalam penelitian ini adalah bagaimana merancang dan membuat alat monitoring kelembaban tanah dan suhu udara pada tanaman berbasis GSM SIM900A dan Arduino Uno, serta mengukur kelembaban tanah dan suhu udara pada tanaman berbasis GSM SIM900A dan Arduino Uno.

\section{METODE PENELITIAN}

Jenis penelitian ini adalah penelitian dan pengembangan (Research and Development). Metode penelitian dan pengembangan (R\&D) adalah metode penelitian yang digunakan untuk menghasilkan rancangan produk baru, menguji keefektifan produk yang telah ada, serta mengembangkan dan menciptakan produk baru". Menurut Richey and Klein (2009) ada tiga langkah penelitian dan pengembangan, yaitu dimulai dengan tahap planning (perencanaan), kemudian production (produksi), dan terakhir evaluation (evaluasi) [4].

Tahap planning, diawali dengan analisis kebutuhan yang dilakukan melalui studi literatur ataupun pengumpulan informasi yang berkaitan dengan penelitian untuk dilakukan perancangan. 
Selanjutnya dilakukan tahap production (produksi), pada tahap ini akan dilakukan pembuatan produk sesuai dengan rancangan yang telah dibuat. Adapun produk yang dirancang dalam penelitian ini adalah alat monitoring kelembaban tanah dan suhu udara berbasis GSM SIM900A dan Arduino Uno. Setelah tahap produksi selesai maka tahapan terakhir yang dilakukan adalah evaluation (evaluasi), pada tahap evaluasi ini dilakukan kegiatan pengujian produk, untuk menilai apakah produk yang telah dibuat bekerja dengan baik sesuai dengan tujuan yang telah ditentukan.

Dalam penelitian ini tahapan evaluasi dilakukan dengan cara pengujian produk secara keseluruhan. Untuk sensor DHT11 dalam penelitian ini, nilai yang terbaca pada sensor DHT11 akan dibandingkan dengan nilai pada termometer ruangan digital. Sedangkan Soil Moisture sensor dilakukan teknik kalibrasi secara eksternal dengan cara menancapkan probe pada kondisi tanah yang berbeda mulai dari kondisi kering, lembab hingga basah.

\section{HASIL DAN PEMBAHASAN}

\subsection{Planning (Perencanaan)}

Pada tahap perencanaan ini diawali dengan analisis kebutuhan yang dilakukan melalui studi literatur ataupun pengumpulan informasi yang berkaitan dengan penelitian. Dalam mengembangkan sistem monitoring kelembaban tanah dan suhu pada tanaman ini mengacu pada beberapa penelitian sebelumnya yaitu, Prayitno, (2017) [3], Sistem Monitoring Suhu, Kelembaban, dan Pengendali Penyiraman Tanaman Hidroponik menggunakan Blynk Android, Yahwe, dkk (2016) [2], Rancang Bangun Prototype System Monitoring Kelembaban Tanah Melalui SMS Berdasarkan Hasil Penyiraman Tanaman "Studi Kasus Tanaman Cabai Dan Tomat".

Berdasarkan studi literatur di atas, diperoleh komponen apa saja yang dibutuhkan serta rancangan dari produk yang dikembangkan. Selanjutnya dilakukan perancangan perangkat keras (hardware) dan perangkat lunak (software). Perancangan perangkat keras diawali dengan merancang diagram blok terlebih dahulu. Adapun diagram blok dari rancang bangun sistem monitoring kelembaban tanah dan suhu dapat dilihat pada Gambar 1.

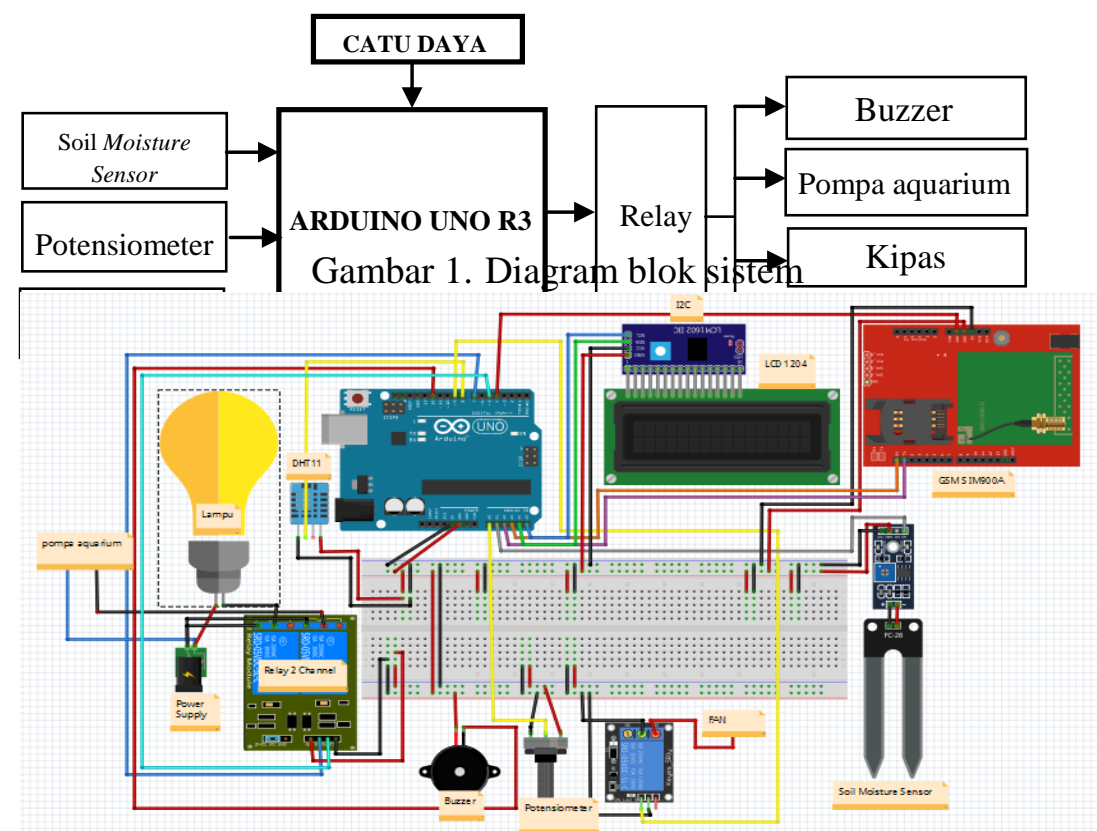

Gambar 2. Design Rangkaian Elekttronik

Gambar 2 adalah skema rangkaian gabungan dari beberapa rangkaian komponen perangkat keras menjadi satu rangkaian menyeluruh. Seperti yang ditunjukkan pada Gambar 2 bahwa Arduino Uno berfungsi sebagai komponen utama dalam mengendalikan sistem. Sedangkan GSM SIM900A berfungsi sebagai receiver dari sistem. GSM SIM900A akan menerima input dari Arduino lalu GSM SIM900A memproses data yang diterima dari Arduino untuk dikirim berupa SMS (Short Message Service) pemberitahuan kepada pemilik tanaman jika sensor kelembaban tanah, suhu dan ketinggian air mendeteksi keadaan sesuai dengan yang telah ditentukan sebelumnya.

Selanjutnya dilakukan perancangan perangkat lunak (software). Perancangan perangkat lunak terfokus pada pemrograman Arduino dengan menggunakan perangkat lunak Arduino IDE (Integrated 
Development Environment) untuk membuat kode program. Sedangkan untuk perancangan elektronik pada alat ini dirancang dengan menggunakan aplikasi fritzing.

\subsection{Production (Produksi)}

Pada tahap ini sudah dilakukan pembuatan produk sesuai dengan rancangan yang telah dibuat. Kegiatan produksi ini dilakukan untuk menghasilkan sebuah alat yang dapat digunakan untuk memonitoring kelembaban tanah dan suhu ruangan pada tanaman sawi melalui SMS. Sebelum dilakukan pembuatan alat sudah dilakukan pengujian untuk tiap komponen elektronik yang digunakan. Hal ini dilakukan untuk memastikan bahwa alat yang digunakan dalam keadaan baik dan dapat bekerja sesuai dengan fungsinya.

Setelah melakukan pengujian tiap komponen selanjutnya dilakukan penggabungan semua komponen untuk menghasilkan sistem yang dapat memonitoring kelembaban tanah dan suhu pada tanaman. Pertama dilakukan pembuatan rumah tanaman dengan menggunakan kayu dan diatapi dengan plastik. Kemudian melubangi paralon sebagai tempat pengaliran air pada tanaman. Kemudian merakit setiap komponen yang digunakan.

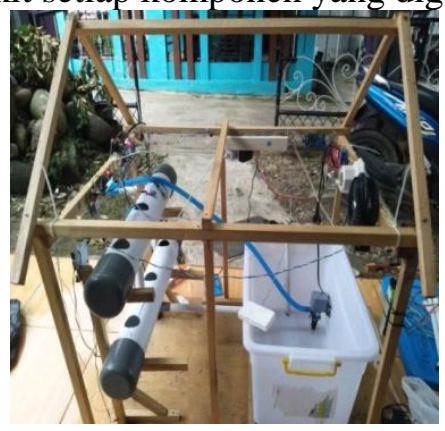

Gambar 3. Rumah Tanaman

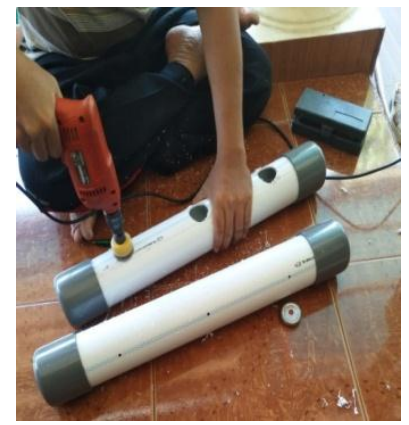

Gambar 4. Pelubangan Paralon

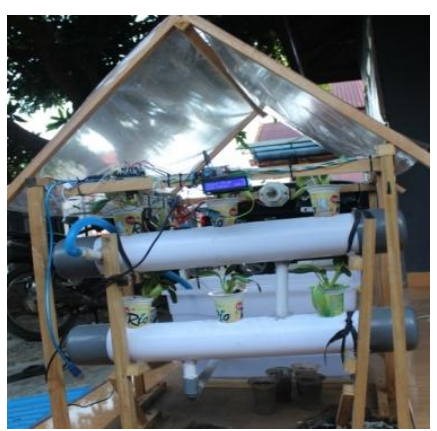

Gambar 5. Keseluruhan Sistem

\subsection{Evaluation (Evaluasi)}

Pada tahap evaluasi ini sudah dilakukan kegiatan menguji alat monitoring kelembaban tanah dan suhu melalui SMS. Adapun hasil pengujian alat secara keseluruhan sekaligus sebagai data hasil pengukuran suhu dan kelembaban tanah dapat dilihat pada Tabel 1.

Tabel 1. Hasil Pengujian Keseluruhan Sistem

\begin{tabular}{|c|c|c|c|c|c|c|c|c|c|c|c|}
\hline \multirow[t]{2}{*}{ No. } & \multirow[t]{2}{*}{ Jam } & \multicolumn{2}{|r|}{ Suhu } & \multicolumn{2}{|c|}{$\begin{array}{c}\text { Kelembaban } \\
\text { Tanah }\end{array}$} & \multirow{2}{*}{$\begin{array}{l}\text { t.air } \\
(\mathrm{cm})\end{array}$} & \multirow[t]{2}{*}{ Buzzer } & \multirow[t]{2}{*}{ SMS } & \multicolumn{3}{|c|}{ Relay } \\
\hline & & ${ }^{\circ} \mathrm{C}$ & Kondisi & $\%$ & Kondisi & & & & $\mathrm{L}$ & $\mathrm{K}$ & $\mathrm{P}$ \\
\hline 1 & 20.04 & 29 & Aman & 62,5 & Basah & 1 & ON & $\sqrt{ }$ & OFF & OFF & OFF \\
\hline 2 & 20.07 & 29 & Aman & 62,5 & Basah & 9,1 & OFF & $\sqrt{ }$ & OFF & OFF & OFF \\
\hline 3 & 20.10 & 29 & Aman & 62,4 & Basah & 9,1 & OFF & $\sqrt{ }$ & OFF & OFF & OFF \\
\hline 4 & 20.13 & 29 & Aman & 62,4 & Basah & 9,1 & OFF & $\sqrt{ }$ & OFF & OFF & OFF \\
\hline 5 & 20.16 & 29 & Aman & 61,1 & Basah & 9,1 & OFF & $\sqrt{ }$ & OFF & OFF & OFF \\
\hline 6 & 20.19 & 29 & Aman & 61,1 & Basah & 9,1 & OFF & $\sqrt{ }$ & OFF & OFF & OFF \\
\hline 7 & 20.22 & 29 & Aman & 60,4 & Basah & 8,5 & OFF & $\sqrt{ }$ & $\mathrm{OFF}$ & OFF & OFF \\
\hline 8 & 20.25 & 29 & Aman & 60,4 & Basah & 8,5 & OFF & $\sqrt{ }$ & OFF & OFF & OFF \\
\hline 9 & 20.28 & 29 & Aman & 59,3 & Basah & 8,5 & OFF & $\sqrt{ }$ & OFF & OFF & OFF \\
\hline 10 & 20.31 & 29 & Aman & 59,3 & Basah & 8,5 & OFF & $\sqrt{ }$ & OFF & OFF & OFF \\
\hline
\end{tabular}

Keterangan : $\mathrm{L}=\mathrm{Lampu}, \mathrm{K}=$ Kipas, $\mathrm{P}=$ Pompa Aquarium, $\sqrt{ }=$ terkirim, t.air $=$ tinggi air

Aman $=$ kondisi ideal untuk tanaman sawi, Jam = waktu dilakukan pengukuran.

Tabel 1 adalah hasil pengukuran suhu, kelembaban tanah dan tindakan pada tiap-tiap kondisi. Adapun data kondisi suhu yang diperoleh dari sensor DHT11 dibandingkan dengan hasil pengukuran dari termometer ruangan digital. Suhu yang terukur oleh sensor DHT11 mendekati suhu yang terukur dari termometer ruangan digital.

Selanjutnya data kelembaban tanah diperoleh dari soil moisture sensor. Pada pengukuran kelembaban tanah sensor dikalibrasi terlebih dahulu, agar mendapatkan data yang akurat. Kalibrasi dilakukan dengan cara menancapkan probe pada kondisi tanah yang berbeda mulai dari kondisi kering, lembab, hingga basah [5]. Data hasil kalibrasi sensor dapat dilihat pada Gambar 6. 


\begin{tabular}{|c|c|c|}
\hline (2) COM12 (Arduino/Genuino Un & Nilai Kelembaban $=516$ & Nilai Kelembaban $=495$ \\
\hline 1 & Nilai Kelembaban $=517$ & Nilai Kelembaban $=494$ \\
\hline 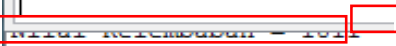 & N1lal Kelembaban $=517$ & Nilai Kelembaban $=492$ \\
\hline Nilai Kelembaban $=1011$ & Nilai Kelembaban $=518$ & Nilai Kelembaban $=402$ \\
\hline Nilai Kelembaban $=508$ & Nilai Kelembaban $=518$ & Nila1 Kelembaban $=388$ \\
\hline Nilai Kelembaban $=552$ & Nilai Kelembaban $=518$ & $\checkmark$ Autoscroll \\
\hline Nilai Kelembaban $=561$ & Nilai Kelembaban $=519$ & \\
\hline
\end{tabular}

Gambar 6. Data Hasil Kalibrasi Soil Moisture Sensor

Berdasarkan hasil pengujian yang diperoleh, hasil pengukuran sensor menunjukkan tiga kondisi yang berbeda dari tanah yang kering, lembab hingga basah.

Tabel 2. Hasil Kalibrasi Soil Moisture Sensor

\begin{tabular}{ccc}
\hline Nilai sensor & $\%$ & Kondisi Tanah \\
\hline $0-388$ & $0-37,92$ & Kering \\
\hline $388-518$ & $38,02-50,6$ & Lembab \\
\hline $518-1011$ & $50,7-98,82$ & Basah \\
\hline
\end{tabular}

Dari nilai sensor yang diperoleh dapat dicari nilai minimum dengan menggunakan bacaan sensor saat kondisi kering dan untuk nilai maksimum dengan menggunakan bacaan sensor saat kondisi basah. Sehinngga pada kondisi kering hasilnya adalah $1023-1011=12$, dan pada kondisi basah adalah $1023-388=635$. Data ini dijadikan referensi proses kalibrasi sensor yang memiliki rentang pengukuran 12 sampai dengan 635.

Selanjutnya data hasil pengukuran dari sensor dikirim oleh GSM SIM900A kepada pemilik tanaman dalam bentuk SMS, dengan ketentuan jika kelembaban tanah yang terbaca oleh sensor $<400$ berarti kondisi kelembaban tanah rendah, dan GSM SIM900A akan mengirimkan pesan dengan teks "kelembaban tanah kurang. Mohon disiram", kemudian secara otomatis relay akan aktif untuk menghidupkan pompa air, jika sudah mencapai kelembaban yang diinginkan maka pompa secara otomatis akan mati sedangkan jika nilai sensor yang terbaca >600 maka berarti kondisi kelembaban tanah tinggi atau dalam kondisi lembab dan GSM SIM900A juga akan mengirimkan pesan dengan teks "kelembaban tanah tinggi". Namun apabila kondisi kelembaban tanah yang terdeteksi $\geq 200$ kelembaban tanah $\leq 600$ maka GSM SIM900A akan mengirimkan pesan pada user yang berisi "kelembaban tanah aman". Alat ini juga sudah dibuat bak penampung air untuk menyiram tanaman, pada bak penampung digunakan potensiometer untuk memantau persediaan air, jika air pada bak penampung habis maka buzzer akan hidup sebagai alarm pemberitahuan bahwa air pada bak penampung habis dan GSM SIM900A akan mengirimkan pesan kepada user dengan teks yang berisi "volume air habis". Setiap kondisi suhu, kelembaban tanah, dan ketinggian air akan dikirim dengan modul GSM SIM900A kepada user. Dalam proses pengiriman kondisi tanaman tergantung pada sinyal kartu sim yang digunakan.Pengiriman informasi keadaan tanaman yang dikirim Modul GSM SIM900A kepada user dapat dilihat pada Gambar 7.

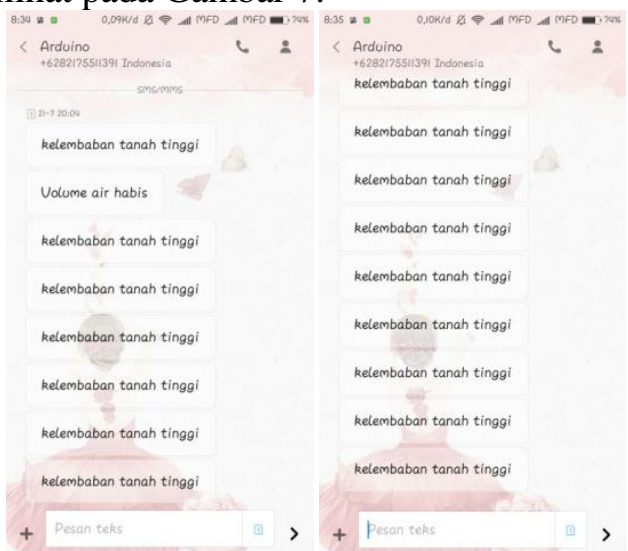

Gambar 7. SMS informasi yang dikirim Modul GSM SIM900A

Dari semua pengujian yang telah dilakukan, dapat dijelaskan bahwa sistem monitoring kelembaban tanah dan suhu udara berbasis GSM SIM900A dan Arduino Uno ini berfungsi sesuai dengan yang direncanakan. Setiap perangkat keras seperti, Arduino Uno, soil moisture sensor, sensor DHT11, Modul GSM SIM900A potensiometer, LCD, dan relay dapat berfungsi dengan baik. Hal ini dibuktikan dari kerja sistem yang dapat berfungsi dengan baik sesuai keadaan yang ditentukan.

\section{SIMPULAN DAN SARAN}

4.1 Simpulan 
Berdasarkan penelitian yang telah dilakukan dan pembahasan yang telah diuraikan, maka dapat disimpulkan bahwa: (1) Alat monitoring kelembaban tanah dan suhu pada tanaman berbasis GSM SIM900A dan Arduino Uno dirancang dengan dua tahapan, yaitu perancangan hardware dan perancangan software. Pada tahap perancangan hardware dilakukan pembuatan diagram blok yang dibuat dengan menggunakan Microsoft Word dan rancangan elektronik dirancang dengan menggunakan aplikasi Fritzing. Sedangkan pada perancangan software terdiri dari perancangan diagram alir yang dibuat dengan menggunakan Microsoft Word. (2) Alat monitoring kelembaban tanah dan suhu pada tanaman berbasis GSM SIM900A dan Arduino Uno dibuat dari beberapa komponen yang saling terhubung yang terdiri dari sensor DHT11 untuk mengukur suhu ruangan, soil moisture sensor untuk mengukur tingkat kelembaban tanah, GSM SIM900A yang berfungsi sebagai pengirim Short Message Service (SMS) kepada user, dan Arduino Uno sebagai kontrol utama dari rangkaian yang saling terhubung. Adapun rangkaian elekronik lainnya seperti buzzer, kipas, LCD, dan pompa air sudah dapat berfungsi dengan baik sesuai dengan rancangan yang sudah dibuat dan sesuai dengan kode program yang ditanamkan. (3) Kelembaban tanah pada alat ini diukur dengan menggunakan soil moisture sensor dengan cara manancapkan probe pada tanah. Jika nilai yang dihasilkan sensor kecil berarti tanah dalam keadaan kering namun ketika nilai sensor yang dihasilkan besar berarti tanah dalam keadaan lembab. Sedangkan pengukuran suhu udara dilakukan dengan menggunakan sensor DHT11, nilai yang dihasilkan sensor dibandingkan dengan termometer ruangan digital dan nilai yang dihasilkan tidak jauh berbeda.

\subsection{Saran}

Untuk pengembangan lanjutan dari alat yang sudah dibuat, sebaiknya menggunakan plastik UV agar suhu dan kelembaban udara pada siang hari dapat terjaga. Dengan demikian tidak akan membakar daun pada tanaman karena penerimaan cahaya yang berlebihan dan juga saat hujan plastik UV akan melindungi tanaman agar air hujan tidak masuk dan mengenangi tanaman.

\section{UCAPAN TERIMA KASIH}

Dengan terselesaikannya penelitian ini, penulis mengucapkan terima kasih yang sedalamdalamnya kepada bapak Dedy Hamdani, M.Si selaku pembimbing utama dan bapak Eko Risdianto, M.Cs selaku pembimbing pendamping.

\section{DAFTAR PUSTAKA}

[1] Samadi, B. (2017). Teknik Budidaya Sawi dan Pak Choy. Jakarta: Pustaka Mina.

[2] Yahwe, C. P., Isnawaty, \& Aksara, L. F. (2016). Rancang Bangun Prototype System Monitoring Kelembaban Tanah Melalui SMS Berdasarkan HasilL Penyiraman Tanaman "Studi Kasus Tanaman Cabai dan Tomat". semanTIK. Vol 2 (1): 98.

[3] Prayitno, W. A., Muttaqin, A., \& Syauqy, D. (2017). Sistem Monitoring Suhu, Kelembaban, dan Pengendali Peyiraman Tanaman Hidroponik menggunakan Blynk Android. Pengembangan Teknologi Informasi dan Ilmu Komputer. Vol 1 (4), 292.

[4] Sugiyono. (2017). Metode Penelitian dan Pengembangan Research and Development. Bandung: ALFABETA.

[5] Sabirin, Muhammad, Triyanto, Dedi, \& Suhardi. (2018). Implementasi Wireless Sensor Network pada Sistem Pemantauan dan Pengontrolan Budidaya Tanaman pada Rumah Kaca (Green House) Berbasis Website. Sistem Komputer Untan. Vol 06 (1): 26. 